\title{
Analisis Kinerja Gabungan Metode Ensemble Empirical Mode Decomposition Dan Generalized Regression Neural Network
}

(Studi Kasus : Peramalan Harga Minyak Mentah)

\author{
Sri Herawati ${ }^{1}$, M. Latif $^{2}$ \\ ${ }^{1,2}$ Fakultas Teknik,Universitas Trunojoyo \\ ${ }^{1,2}$ Jl. Raya Telang Po. Box 2 Kamal Bangkalan, 69162 \\ Email korespondensi : zheira83@yahoo.com
}

Dikirim 21 Oktober 2016, Direvisi 11 November 2016, Diterima 12 November 2016

\begin{abstract}
Abstrak - Metode runtun waktu cocok digunakan ketika akan memeriksa setiap pola data secara sistematis dan memiliki banyak variabel bebas, seperti pada kasus harga minyak mentah. Salah satu penelitian yang memanfaatkan metode runtun waktu adalah integrasi antara Ensemble Empirical Mode Decomposition (EEMD) dan jaringan syaraf berdasarkan algoritma Polak-Ribiére Conjugate Gradient (PCG). Jenis jaringan syaraf menggunakan FeedForward Neural Network (FNN). Namun, FNN memerlukan pengaturan parameter bebas dalam proses pembelajarannya. Sementara, parameter yang sesuai sangat dibutuhkan untuk mendapatkan hasil peramalan yang akurat. Penelitian ini mengusulkan integrasi antara EEMD dan Generalized Regression Neural Network (GRNN). GRNN memiliki keunggulan, yaitu: tidak memerlukan pengaturan parameter dan proses pembelajaran yang cepat. Untuk evaluasi, kinerja metode EEMD-GRNN dibandingkan dengan GRNN. Hasil eksperimen menunjukkan bahwa metode EEMD-GRNN menghasilkan peramalan yang lebih baik dari GRNN. Metode EEMD-GRNN memiliki nilai MSE dan RMSE lebih kecil daripada GRNN. Nilai MSE dan RMSE menggunakan data pengujian untuk WTI berturut-turut sebesar 0,0032 dan 0,0569. Sementara, Nilai MSE dan RMSE menggunakan data pengujian Brent berturut-turut sebesar 0,0017 dan 0,0415.
\end{abstract}

Kata kunci - Peramalan Harga Minyak Mentah, EEMD, GRNN.

\begin{abstract}
The method of time series suitable for use when it checks each data patterns systematically and has many variables, such as in the case of crude oil prices. One study that utilizes the methods of time series is the integration between Ensemble Empirical Mode Decomposition (EEMD) and neural network algorithms based on Polak-Ribiere Conjugate Gradient (PCG). Type of neural network using Feedforward Neural Network (FNN). However, FNN requires setting free parameters in the learning process. Meanwhile, the appropriate parameters are needed to get accurate forecasting results. This research proposes the integration between EEMD and Generalized Regression Neural Network (GRNN). GRNN has advantages, such as: does not require any parameter settings and a quick learning process. For the evaluation, the performance of the method EEMDGRNN compared with GRNN. The experimental results showed that the method EEMD-GRNN produce better forecasting of GRNN. Method of EEMD-GRNN has a value of MSE and RMSE smaller than GRNN. The value of MSE and RMSE used test data for WTI successively equal 0.0032 and 0.0569 . While the value of MSE and RMSE used test data for Brent successively equal 0,0017 and 0,0415.
\end{abstract}

Keywords - Forecasting crude oil price, EEMD, GRNN

\section{PENDAHULUAN}

Metode runtun waktu merupakan salah satu alternatif yang digunakan dalam peramalan, dimana data masa depan berasal dari data historis masa lalu. Metode ini menggunakan pola hubungan antara variabel yang akan diramal dengan variabel waktu. Sebagian besar metode runtun waktu cocok digunakan ketika akan memeriksa setiap pola data secara sistematis dan memiliki banyak variabel bebas [1], seperti pada kasus harga minyak mentah. Harga minyak ini dipengaruhi variabel yang berasal dari peristiwa masa lalu, sekarang, dan masa depan yang tidak teratur seperti perang, resesi ekonomi global [2], ketidakseimbangan antara permintaan dan persedian [3] [4], aspek politik [5], dan sebagainya.

Beberapa penelitian telah dilakukan dengan menggunakan metode runtun waktu untuk peramalan harga minyak mentah. Salah satu contohnya, penelitian menggunakan GARCH yang dibandingkan dengan model volatilitas [6]. Kemudian, penelitian mengenai integrasi antara ARIMA dan GARCH [7]. 
Sebenarnya, fluktuasi harga minyak mentah cenderung nonlinear, sehingga kurang cocok menggunakan pemodelan ARIMA [8]. Untuk mengakomodasi fluktuasi nonlinear tersebut, penelitian [9] mengintegrasikan Ensemble Empirical Mode Decomposition (EEMD) dan jaringan syaraf berdasarkan algoritma Polak-Ribiére Conjugate Gradient (PCG). Jenis jaringan syaraf menggunakan FeedForward Neural Network (FNN). EEMD digunakan untuk menganalisis harga minyak mentah, sedangkan FNN menggunakan algoritma PCG untuk mempercepat proses pembelajaran jaringan syaraf tiruan.

Namun untuk proses pembelajaran, FNN memerlukan pengaturan parameter bebas. Sementara parameter yang sesuai sangat dibutuhkan untuk mendapatkan hasil peramalan yang akurat. Salah satu jenis jaringan syaraf tiruan yang tidak memerlukan pengaturan parameter adalah Generalized Regression Neural Network (GRNN) [10]. Oleh karena itu, tujuan penelitian ini adalah untuk menghasilkan peramalan dari integrasi antara metode EEMD dan GRNN. Selain itu, penelitian juga melakukan analisis terhadap kinerja peramalan integrasi EEMD-GRNN dibandingkan dengan GRNN.

\section{METODOLOGI PENELITIAN}

Metodologi penelitian dilakukan seperti pada Gambar 2.

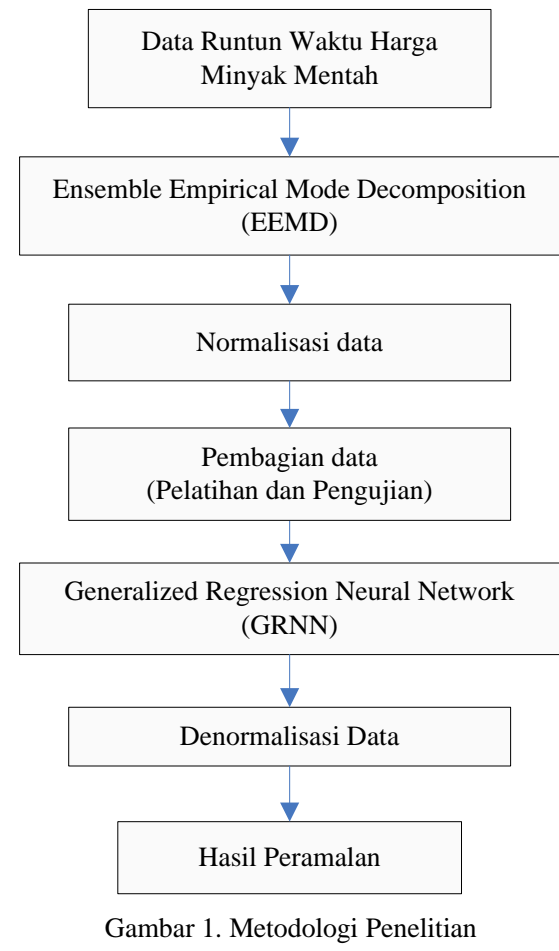

Seperti yang ditampilkan pada Gambar 1, diagram alir hampir sama dengan penelitian yang dilakukan Latif dan Herawati [9]. Namun, perbedaan penelitian ini adalah menggunakan GRNN untuk menggatikan fungsi Feedforward Neural Network
(FNN). Penggantian ini dilakukan untuk mendapatkan hasil peramalan yang lebih akurat. Kemudian, hasil peramalan akan dibandingkan dengan metode GRNN untuk menguji akurasinya.

\section{A. Data Runtun Waktu Harga Minyak Mentah}

Penelitian ini juga menggunakan data bulanan harga minyak mentah jenis WTI dan Brent. Data WTI dimulai dari bulan Januari 1986 sampai dengan Januari 2015, sedangkan Brent dimulai dari bulan Mei 1987 sampai Januari 2015.

\section{B. Ensemble Empirical Mode Decomposition (EEMD)}

EEMD merupakan salah satu metode analisis data yang dikembangkan dari Empirical Mode Decomposition (EMD). EEMD dapat menghasilkan dekomposisi yang lebih baik daripada EMD dengan menambahkan white noise pada data [11]. Penambahan white noise dapat dikontrol sesuai dengan aturan statistik yang terbukti baik menggunakan Persamaan (1).

$$
\varepsilon_{\mathrm{m}}=\frac{\varepsilon}{\sqrt{\mathrm{M}}}
$$

dimana $\mathrm{M}$ merupakan jumlah anggota ensemble, $\varepsilon$ merupakan amplitudo penambahan derau, dan $\varepsilon_{\mathrm{m}}$ merupakan standar deviasi akhir untuk error yang didefinisikan sebagai perbedaan antara sinyal input dan korespondensi IMFs [12].

\section{Generalized Regression Neural Network}

Generalized Regression Neural Network (GRNN) adalah jenis jaringan syaraf tiruan dengan keunggulan proses pembelajaran cepat dan konvergensi yang optimal [13]. GRNN termasuk dalam jaringan dengan pelatihan terawasi. Model GRNN ini sering digunakan untuk mengatasi permasalahan peramalan, seperti : nilai tukar mata uang [14], dan kunjungan wisatawan [10]. Kinerja peramalan menunjukkan hasil yang baik.

Berdasarkan arsitektur GRNN seperti yang ditunjukkan pada Gambar 2 dapat dilihat bahwa GRNN memiliki empat layer, antara lain layer masukan, layer radial basis, layer penggabungan, dan layer keluaran [15]. Layer radial basis menggabungkan dan memproses informasi secara sistematis agar dapat mempelajari hubungan antara variabel input dan output. Dalam proses tersebut, layer radial basis akan menggunakan fungsi aktivasi.

Dalam GRNN, akurasi peramalan menggunakan nilai Mean Squared Error (MSE) dan Root Mean Squared Error (RMSE). Persamaan MSE dapat dilihat pada Persamaan (2), sedangkan RMSE dapat dilihat pada Persamaan (3).

$$
\begin{aligned}
& M S E=\frac{1}{n} \sum_{t=1}^{n}\left(A_{t}-F_{t}\right) \\
& R M S E=\sqrt{\frac{1}{n} \sum_{t=1}^{n}\left(A_{t}-F_{t}\right)}
\end{aligned}
$$


dimana $\mathrm{A}_{\mathrm{t}}$ merupakan data aktual harga minyak mentah pada waktu ke-t. $F_{t}$ merupakan data hasil peramalan pada waktu ke-t dan $n$ adalah jumlah data. Semakin kecil nilai MSE dan RMSE, maka hasil peramalan akan semakin akurat.

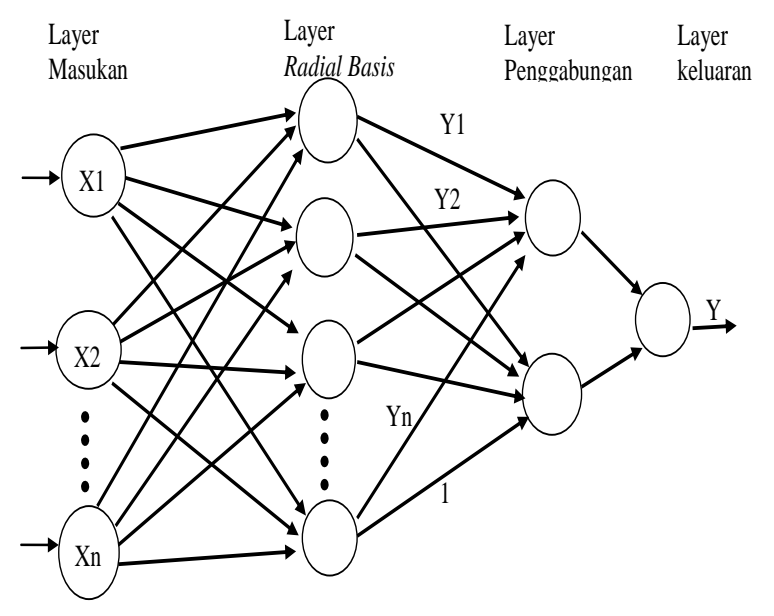

Gambar 2. Arsitektur GRNN

\section{HASIL DAN PEMBAHASAN}

Pada penelitian ini dilakukan perbandingan kinerja peramalan menggunakan gabungan metode EEMD dan GRNN dengan metode GRNN. Perbandingan dilakukan dengan menggunakan nilai MSE dan RMSE. Nilai spread menggunakan nilai spread 0.08 untuk data WTI dan spread 0.07 untuk data Brent. Sementara, input data menggunakan variasi skenario antara lain.

1. Skenario 1 : input data menggunakan $t_{-1}$.

2. Skenario 2 : input data menggunakan $t_{-1}$ dan $t_{-2}$.

3. Skenario 3 : input data menggunakan $t_{-1} t_{-2}$ dan $t_{-3}$

4. Skenario 4 : input data menggunakan $t_{-1} t_{-2} t_{-3}$ dan $t_{-}$.

5. Skenario 5 : input data menggunakan $t_{-1} t_{-2} t_{-3} t_{-4}$ dan $\mathrm{t}_{-5}$.

Penjelasan skenario diatas adalah jika jaringan dengan input data $t_{-1}$ dan $t_{-2}$, maka jaringan ini memiliki dua unit input yang berasal dari data aktual ke-1 dan ke-2 harga minyak mentah. Vektor input tersebut ditulis dengan $\mathrm{X}_{\mathrm{t}-1}$ dan $\mathrm{X}_{\mathrm{t}-2}$. Hasil perbandingan kinerja peramalan untuk data WTI ditunjukkan pada Tabel 1 dan data Brent ditunjukkan pada Tabel 2.

Tabel 1. Perbandingan Hasil Peramalan Untuk Data WTI

\begin{tabular}{|c|c|c|c|c|c|c|c|c|c|c|}
\hline \multirow{2}{*}{ Metode } & \multicolumn{2}{|c|}{ Skenario 1} & \multicolumn{2}{|c|}{ Skenario 2} & \multicolumn{2}{|c|}{ Skenario 3} & \multicolumn{2}{|c|}{ Skenario 4} & \multicolumn{2}{|c|}{ Skenario 5} \\
\hline & MSE & RMSE & MSE & RMSE & MSE & RMSE & MSE & RMSE & MSE & RMSE \\
\hline GRNN & 0,0073 & 0,0852 & 0,0075 & 0,0864 & 0,0077 & 0,0878 & 0,0087 & 0,0932 & 0,0129 & 0,1136 \\
\hline EEMD-GRNN & 0,0054 & 0,0732 & 0,0042 & 0,0651 & 0,0032 & 0,0569 & 0,0037 & 0,0608 & 0,0038 & 0,0618 \\
\hline
\end{tabular}

Tabel 2. Perbandingan Hasil Peramalan Untuk Data Brent

\begin{tabular}{|c|c|c|c|c|c|c|c|c|c|c|}
\hline \multirow{2}{*}{ Metode } & \multicolumn{2}{|c|}{ Skenario 1} & \multicolumn{2}{|c|}{ Skenario 2} & \multicolumn{2}{|c|}{ Skenario 3} & \multicolumn{2}{|c|}{ Skenario 4} & \multicolumn{2}{|c|}{ Skenario 5} \\
\hline & MSE & RMSE & MSE & RMSE & MSE & RMSE & MSE & RMSE & MSE & RMSE \\
\hline GRNN & 0,0050 & 0,0707 & 0,0058 & 0,0762 & 0,0112 & 0,1058 & 0,0164 & 0,1279 & 0,0192 & 0,1385 \\
\hline EEMD-GRNN & 0,0081 & 0,0898 & 0,0031 & 0,0559 & 0,0017 & 0,0415 & 0,0025 & 0,0499 & 0,0018 & 0,0425 \\
\hline
\end{tabular}

Berdasarkan Tabel 1 dan Tabel 2 dapat dilihat bahwa kinerja peramalan menggunakan metode EEMD-GRNN dibandingkan dengan GRNN. Metode EEMD-GRNN memiliki nilai MSE dan RMSE terkecil dengan menggunakan skenario 3 untuk data WTI dan Brent. Pada skenario 3 menggunakan vektor input $\mathrm{X}_{\mathrm{t}-1}, \mathrm{X}_{\mathrm{t}-2}$ dan $\mathrm{X}_{\mathrm{t}-3}$. Nilai MSE dan RMSE untuk data WTI berturut-turut sebesar 0,0032 dan 0,0569. Sementara, Nilai MSE dan RMSE untuk data Brent berturut-turut sebesar 0,0017 dan 0,0415. Hasil eksperimen menunjukkan bahwa metode EEMD-
GRNN menghasilkan kinerja peramalan relatif lebih unggul dari GRNN. Hal ini dapat dilihat dari nilai MSE dan RMSE yang dihasilkan metode gabungan EEMD-GRNN lebih kecil daripada GRNN.

Hasil perbandingan MSE dan RMSE untuk metode EEMD-GRNN dan GRNN dapat dilihat dengan lebih mudah menggunakan grafik pada Gambar 3 dan Gambar 4. Pada Grafik tersebut dapat dilihat bahwa metode EEMD-GRNN relatif lebih unggul dibandingkan GRNN. 


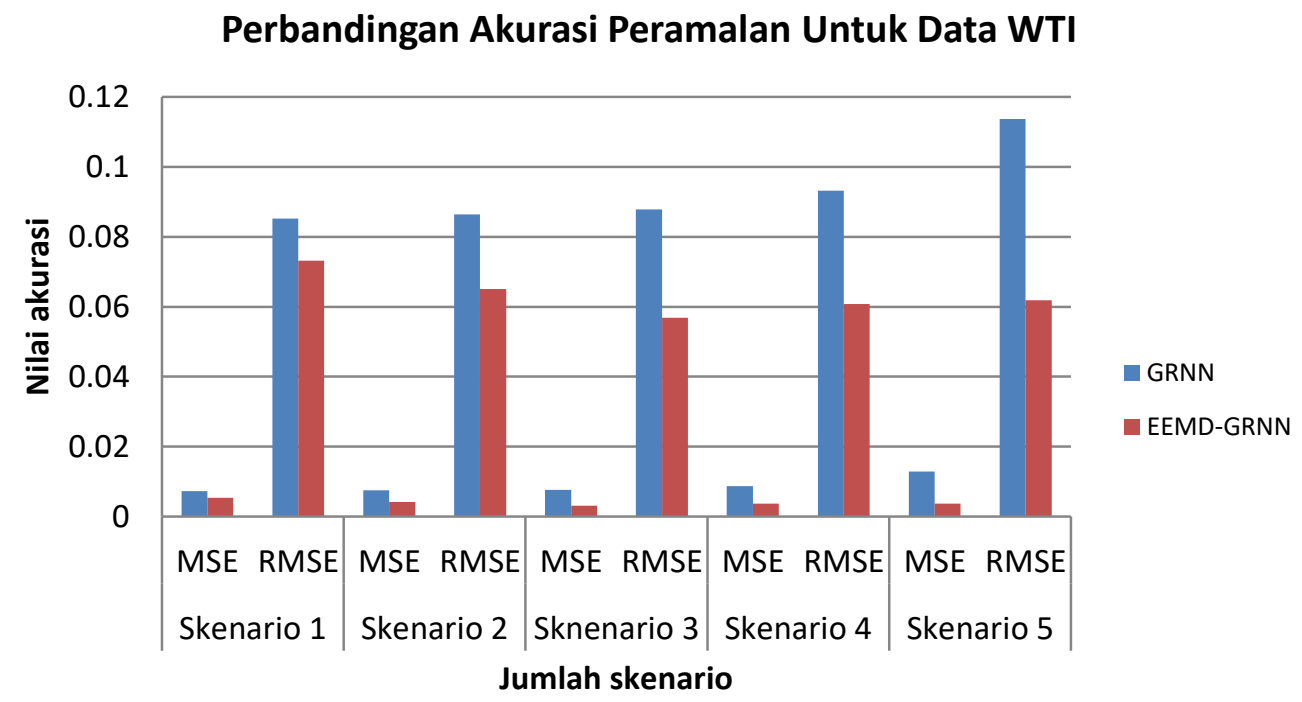

Gambar 3. Grafik Perbandingan Akurasi Peramalan Untuk Data WTI

\section{Perbandingan Akurasi Peramalan Untuk Data Brent}

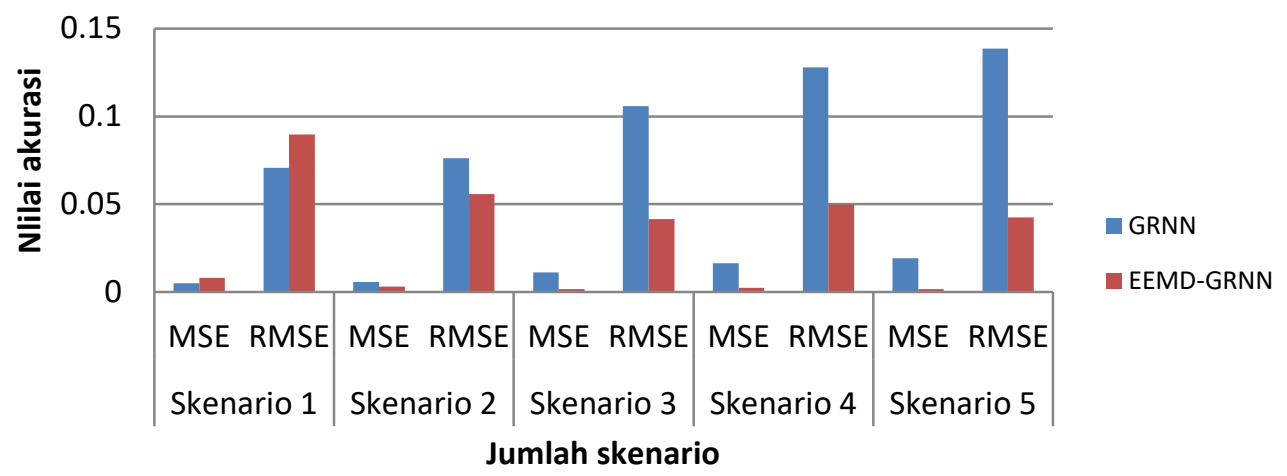

Gambar 4. Grafik Perbandingan Akurasi Peramalan Untuk Data Brent

Perbandingan Hasil Peramalan Untuk Data WTI

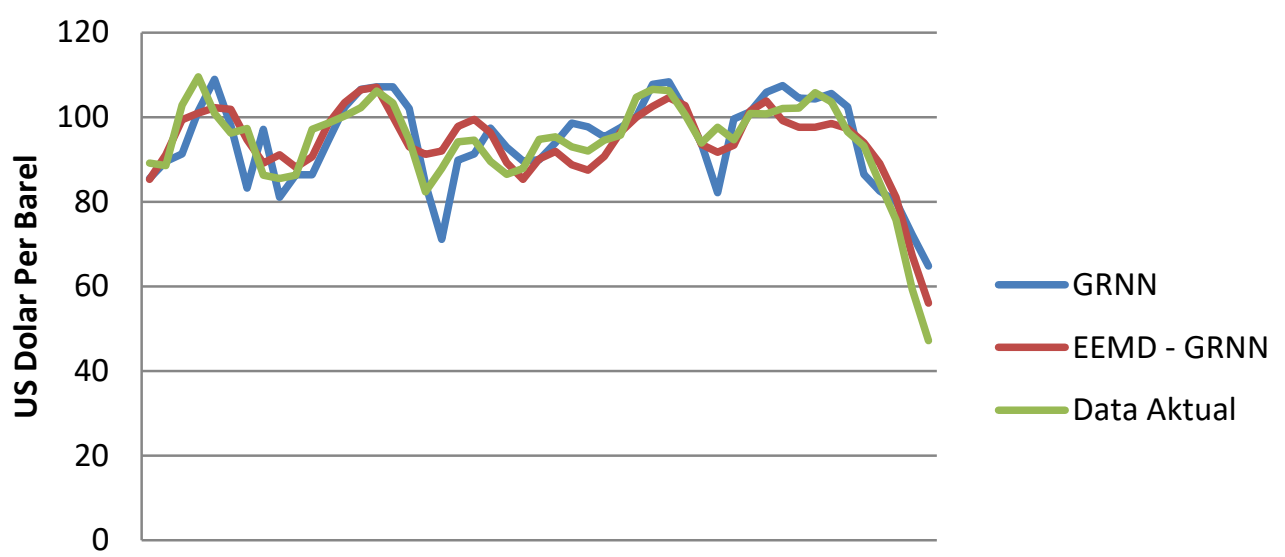

$\begin{array}{lllllllllllllllll}1 & 4 & 7 & 10 & 13 & 16 & 19 & 22 & 25 & 28 & 31 & 34 & 37 & 40 & 43 & 46 & 49\end{array}$

Bulan ke-

Gambar 5. Grafik Perbandingan Hasil Peramalan Untuk Data WTI 
Grafik perbandingan hasil peramalan dengan menggunakan EEMD-GRNN dan GRNN dengan data aktual dapat dilihat pada Gambar 5 dan Gambar 6. Gambar 5 menggunakan data pengujian untuk data WTI, sedangkan Gambar 6 menggunakan data pengujian untuk data Brent. Dari kedua grafik pada
Gambar 5 dan Gambar 6 menunjukkan bahwa kinerja peramalan EEMD-GRNN yang lebih baik dibandingkan GRNN. Kinerja peramalan baik dilihat dari kemiripannya mendekati data aktual harga minyak mentah.

\section{Perbandingan Hasil Peramalan Untuk Data Brent}

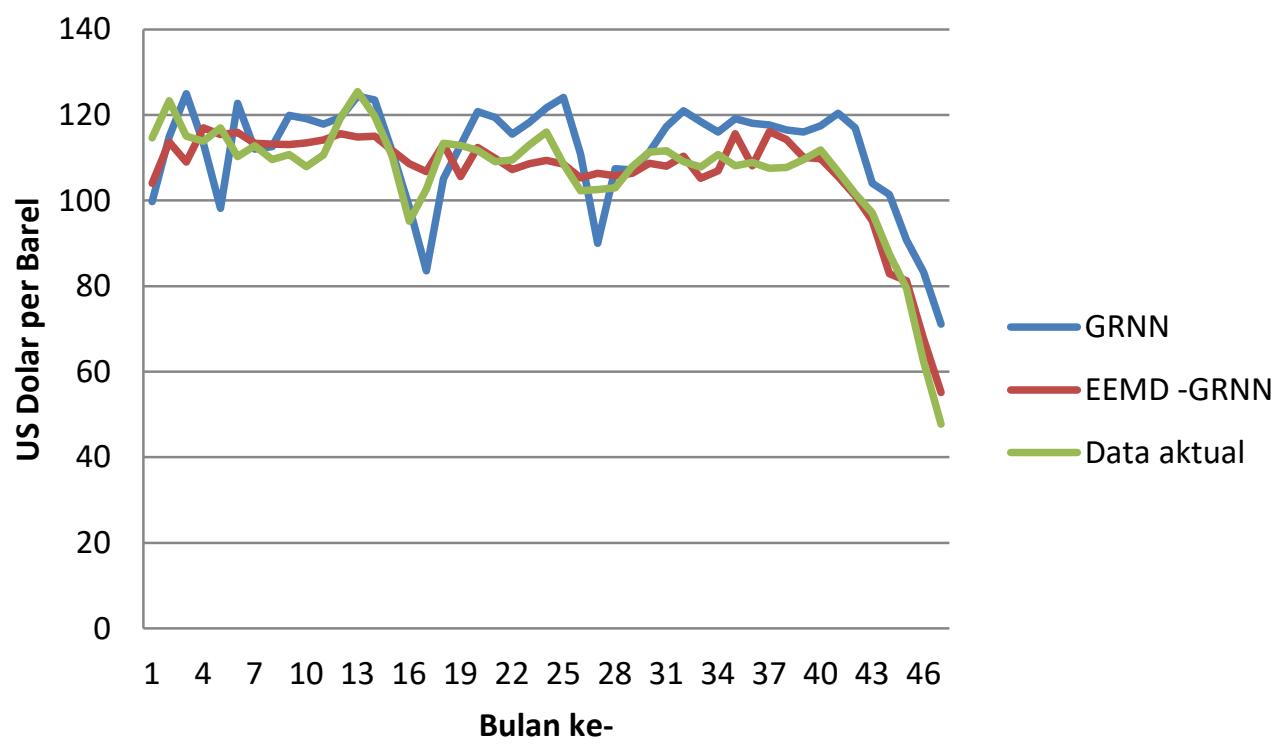

Gambar 6. Grafik Perbandingan Hasil Peramalan Untuk Data Brent

\section{PENUTUP}

\section{A. Kesimpulan}

Hasil penelitian menunjukkan bahwa gabungan metode EEMD dan GRNN lebih baik dari GRNN dalam peramalan harga minyak mentah. Metode EEMD-GRNN memiliki nilai MSE dan RMSE terkecil dengan menggunakan skenario 3 untuk data WTI dan Brent. Nilai MSE dan RMSE menggunakan data pengujian untuk WTI berturut-turut sebesar 0,0032 dan 0,0569. Sementara, Nilai MSE dan RMSE menggunakan data pengujian Brent berturut-turut sebesar 0,0017 dan 0,0415.

\section{UCAPAN TERIMA KASIH}

Penelitian ini didanai oleh Kementerian Riset, Teknologi, dan Pendidikan Tinggi melalui hibah Penelitian Dosen Pemula Tahun 2015.

\section{DAFTAR PUSTAKA}

[1] E. G. de Souza e Silva, L. F. L. Legey, and E. A. de Souza e Silva, "Forecasting oil price trends using wavelets and hidden Markov models," Energy Econ., vol. 32, no. 6, pp. 1507-1519, 2010.

[2] X. Zhang, L. Yu, S. Wang, and K. K. Lai, "Estimating the impact of extreme events on crude oil price: An
EMD-based event analysis method," Energy Econ., vol. 31, no. 5, pp. 768-778, 2009.

[3] Y. Wang, L. Liu, X. Diao, and C. Wu, "Forecasting the real prices of crude oil under economic and statistical constraints," Energy Econ., vol. 51, pp. 599-608, 2015.

[4] X. Jia, H. An, X. Sun, X. Huang, and X. Gao, "Finding the multipath propagation of multivariable crude oil prices using a wavelet-based network approach," Phys. A Stat. Mech. its Appl., vol. 447, pp. 331-344, 2016.

[5] W. Xie, L. Yu, S. Xu, and S. Wang, "A New Method for Crude Oil Price Forecasting Based on Support Vector Machines," Lncs, vol. 3994, pp. 444-451, 2006.

[6] P. Agnolucci, "Volatility in crude oil futures: A comparison of the predictive ability of GARCH and implied volatility models," Energy Econ., vol. 31, no. 2, pp. 316-321, 2009.

[7] H. Mohammadi and L. Su, "International evidence on crude oil price dynamics: Applications of ARIMAGARCH models," Energy Econ., vol. 32, no. 5, pp. 1001-1008, 2010

[8] M. Khashei, M. Bijari, and G. A. Raissi Ardali, "Improvement of Auto-Regressive Integrated Moving Average models using Fuzzy logic and Artificial Neural Networks (ANNs)," Neurocomputing, vol. 72, no. 4-6, pp. 956-967, 2009.

[9] M. Latif and S. Herawati, "The Application of EEMD and Neural Network Based on Polak-Ribiére 
Conjugate Gradient Algorithm for Crude Oil Prices Forecasting," MATEC Web Conf., vol. 58, p. 3013, 2016.

[10] S. Herawati, "Peramalan Kunjungan Wisatawan Mancanegara Menggunakan Generalized Regression Neural Networks," vol. 8, no. 1, pp. 35-39, 2016.

[11] S. Luo, "Application of EEMD in Fault Diagnosis of Diesel Engine,” pp. 465-468, 2010.

[12] K. M. Chang, "Ensemble empirical mode decomposition for high frequency ECG noise reduction," Biomed. Tech., vol. 55, no. 4, pp. 193201, 2010.

[13] S. R. Patil and V. N. Ghate, "Generalized Regression
Neural Network Based on Soft Sensor for Multicomponent Distillation Column," Int. J. Comput. Commun. Eng., vol. 4, no. 6, pp. 371-378, 2015.

[14] M. T. Leung, A.-S. Chen, and H. Daouk, "Forecasting exchange rates using general regression neural networks," Comput. Oper. Res., vol. 27, pp. 10931110, 2000.

[15] M. Theodosiou, "Disaggregation \& aggregation of time series components: A hybrid forecasting approach using generalized regression neural networks and the theta method," Neurocomputing, vol. 74, no. 6, pp. 896-905, 2011. 